\title{
AIS-Ethics as an Ethical Domain: A Response to Guragai, Hunt, Neri and Taylor (2017) and Dillard and Yuthas (2002)
}

Michael Alles. Rutgers Business School, New Jersey, alles@business.rutgers.edu

\begin{abstract}
In this paper, I analyze the claim that AIS-ethics is a distinct subset of the broader fields of accounting and ethical studies. Guragai Hunt, Neri and Taylor (2017), building on Dillard and Yuthas (2002), call for the creation of a subset of business ethics with the intent to not only apply existing ethical concepts to AIS activities, but to establish "AIS-ethics" as a distinct area of practice and research in its own right. Their objective is for AIS-ethics to play the same role in AIS that Bioethics does in medicine. In order to analyze this argument, I analyze the examples provided in the literature on the impact of accounting information systems on ethics. My analysis indicates that there is a need to be more specific as to where exactly ethical issues arise in AIS, and most critical of all, why they do so. Too often, the existence of ethical problems in AIS is presumed to be so self-evident that no further explanation is needed - or provided - about what those ethical issues are, or what the circumstances are that give rise to them. Moreover, the behavior of a decision-maker in an AIS context is sometimes attributed to ethical considerations when a more detailed analysis indicates that the underlying cause of that behavior is either economic and/or not directly impacted by the presence of the AIS system. To remedy this lack of clarity as to what is an ethical problem in AIS, I argue that a necessary condition for individuals to consider that they face a decision with ethical consequences is that they perceive that there is a conflict between their sense of morality and the other sources of guidance relevant to making that decision.
\end{abstract}

Keywords: business ethics, accounting information systems, continuous auditing and monitoring 


\section{INTRODUCTION}

In this paper, I examine an initiative by researchers in Accounting Information Systems (AIS) - in particular, Dillard and Yuthas (2002) and Guragai, Hunt, Neri and Taylor (2017; hereafter GHNT) - to develop a subset of Business Ethics focused on their field ${ }^{1}$. Their intent is not to simply apply existing ethical concepts to AIS activities, but to establish what I call "AIS-ethics" as a distinct area of practice and research in its own right. To play the same role in AIS, for instance, that Bioethics does in the medical profession, not to mention other subspecialties of Business Ethics, such as International Marketing Ethics (Javalgi \& Russell, 2015)2 , Insurance Ethics (Doyle, 2011) and Leadership Ethics (Eubanks et al., 2012). I shall argue in this paper that it is premature to claim that the necessity for AIS-ethics has been proven. The proposed field lacks consensus on what is ethics, what the domain is of AIS and when ethical dilemmas arise in AIS practice.

For millennia, philosophers have thought about what is the ethical way of behaving (i.e. what is "the right thing to do") when faced with a moral dilemma. A classic example of an ethical predicament is the trolley car problem: a bystander observes a runaway trolley car heading towards a group of five people. The observer can save that group by pulling a switch to divert the car onto a branch track, but doing so guarantees killing a person standing on that track (Foot, 1967). What is the "best" way of behaving in this or other morally challenging contexts is the focus of the general study of ethics.

By contrast, a more recent phenomenon in the field of ethics is the attempt to appropriate its domain to specific decision contexts. Thus, there has been a tremendous increase in the attention paid to ethics by many professions and organizations - "Ethics, Ethics Everywhere" as Frost (1992) titled his paper on pediatrics. The aim here is not to answer, "What should a person do when faced with an ethical dilemma?" (since the general study of ethics is trying to figure that

\footnotetext{
${ }^{1}$ Consider the call for papers for the special issue of the Journal of Information Systems on ethics: "Yesterday's AIS were relatively limited observers, recorders, and reporters of data. Due to rapid advances in technology, however, today's AIS are powerful and far-reaching, and create opportunities for individuals who design, implement, and interact with them to intentionally and unintentionally cause harm to individuals, organizations, and societies. Because of this, AIS is at a crossroad with ethics. Universal ethics demand that we, as professionals, academics, and human beings, take on the responsibility of understanding how the systems we create not only help, but also potentially harm others." http://aaahq.org/Research/Calls-For-Submissions/Call-For-Papers-JIS-Themed.

${ }^{2}$ As distinct from Marketing Ethics in general (Schlegelmilch and Öberseder, 2010).
} 
out) but instead to assert "the best person to address the ethical questions that arise in my field are specialists in my field like me."

While this paper focusses on AIS, it might also be interpreted more generally as examining what happens when members of a profession attempt to "own the space" of ethics as applied to their own topical area. AIS researchers such as GHNT are not the first, and nor will they be the last group attempting to create a subset of ethics whose study they claim to have a comparative advantage in (Alles et al., 2008). My analysis examines when creating such a subset is appropriate. Even if it is the case that "ethics are everywhere", that is not to say, as I will show, that every decision is one that has ethical implications. And if the ethical issues encountered in a field such as AIS are common across disciplines, then it undermines the argument that it is practitioners and researchers in that field specifically—as opposed to ethicists in general—who should be the ones helping identify and resolve those ethical problems.

Accounting Information Systems is a field of practice and research concerning the application of technology to all aspects of accounting: from record keeping and processing, to financial reporting and auditing. Corporations have spent billions of dollars on AIS-related technologies, financial statements in the US are now required to be filed digitally (using XBRL tagging) and numerous software vendors offer tools for auditing. In March 2016, KPMG announced that they were teaming up with IBM to apply the latter's famed "Watson artificial-intelligence unit to develop high-tech tools for auditing..." EY recently announced a $\$ 400$ million investment into the application of Big Data analytics to its audit practice, an expenditure paralleled by the other Big-4 professional service firms. ${ }^{4}$ The American Institute of Certified Public Accountants (AICPA, 2015) writes: "The world is evolving and so is the Accounting Profession... Recent technological advances offer both challenges and opportunities that will change the way CPAs operate into the foreseeable future."

Given the size and importance of the AIS business sector and the fact that accounting practice is increasingly becoming technology-based and driven (Vasarhelyi et al., 2010; AICPA, 2015), research into the application of ethics to AIS has seemingly lagged. That is in contrast to the long established literature on

\footnotetext{
3 Wall Street Journal, March $7^{\text {th }}$ ，2016. http://www.wsj.com/articles/auditing-firms-count-on-technology-for-backup1457398380 .

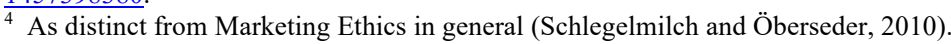


ethics in financial accounting, managerial accounting, auditing and reporting, and especially on Corporate Social Responsibility (CSR) (Briloff, 1972; Dillard \& Yuthas, 2001; Uysal, 2009; Duska et al., 2011; Bampton \& Cowton, 2013; Malik, 2015).

It is in this context that an emerging set of AIS researchers claim that ethics are central to their field. GHNT write: "The foundation of ethics is the understanding of how our behavior affects the well-being of others (Paul \& Elder, 2013). Because people are key elements in AIS, and because managers, regulators, investors, and others use information from AIS to make decisions that affect others (e.g. contracting, hiring, investing, purchasing, and selling), virtually every aspect of AIS has ethical implications."

GHNT visualize in a diagram in their paper the argument that ethical issues are to be found "in every aspect" of AIS. Their diagram, reproduced below, shows ethics spanning the entire activity space of AIS:

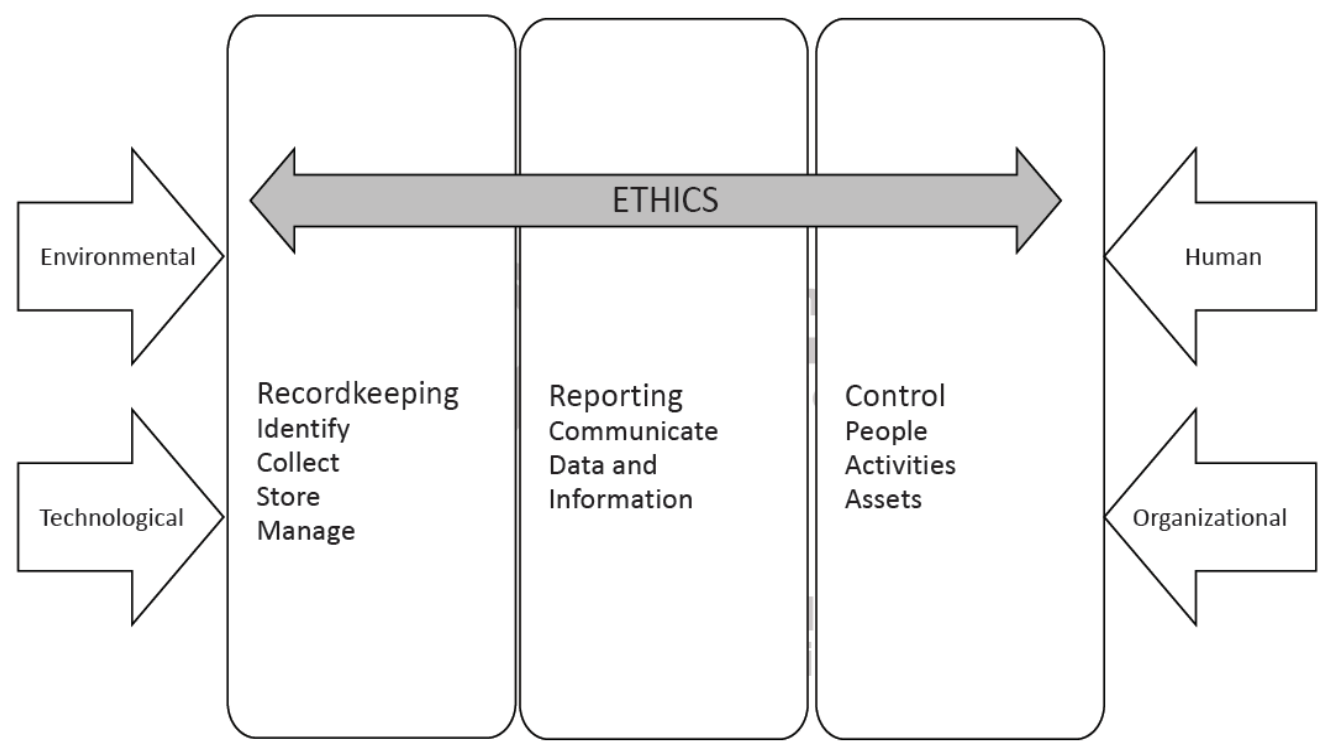

Figure 1. Relationship of AIS Functions, Ethics, and ETHOs Factors from Guragai Hunt, Neri and Taylor $(2017)^{5}$

GHNT are not alone in seeing ethics as central to AIS. In their earlier survey Dillard and Yuthas (2002) write: “... there is a growing recognition that [AIS]

\footnotetext{
${ }^{5}$ Figure 3 from GHNT. The meaning of the term ETHOs is made clear later in this paper.
} 
systems are influenced by the specific conditions under which they exist, and that they motivate organizational and social consequences that go far beyond improved decision-making and task-performance." Indeed, Dillard and Yuthas (2002) concluded that: "The academic community must take the lead in developing and advocating accounting for the public interest that implies a strong grounding in social responsibility and ethical analysis. There are several areas to be addressed. The first is to bring ethics issues and social responsibility into the AIS classroom. The social implications of computer-based information systems must be fully articulated and explored. System attributes beyond efficient use of corporate resources must be recognized as necessary design criteria. System success must be defined in terms of the impact on all affected stakeholders. Applied ethics should become an integral component in the AIS curriculum. Second and not unrelated, academic accounting should move beyond its current role as apologist for the actions and activities of the profession and the proponents of global capitalism. The responsibility of the academic community is to provide an ideologically pluralistic view of the world and above all to commit to overcoming the inherent inequities by exposing exploitative and unethical behavior."

In this paper, I analyze the claim that AIS-ethics is a distinct subset of the broader fields of accounting and ethical studies. While not understating the importance of ethical behavior by those implementing and using AIS systems, I argue that there is a need to be more specific as to where exactly ethical issues arise in AIS, and most critical of all, why they do so. Too often, the existence of ethical problems in AIS is presumed to be so self-evident that no further explanation is needed-or provided - about what those ethical issues are, or what the circumstances are that give rise to them. Moreover, the behavior of a decision-maker in an AIS context is sometimes attributed to ethical considerations when a more detailed analysis indicates that the underlying cause of that behavior is either economic and/or not directly impacted by the presence of the AIS system.

Indeed, what is striking about GHNT and Dillard and Yuthas (2002) is that they provide very few examples of actual ethical quandaries in AIS specifically, and instead give instances from IT in general, such as violations of privacy of customer data and labor deskilling. That is not to say that those issues are not valid ethical problems, for they clearly are. It is harder, though, to make the case 
that there is a need for an AIS-specific field of ethics if the only ethical problems that arise in AIS are those shared with other fields - and, especially when there is already an established literature in those other fields examining those same problems.

One reason for GHNT and Dillard and Yuthas (2002) failure to identify AISspecific ethical issues is that in order to bolster their claim for AIS-ethics as being a stand-alone subset of ethics they attempt to lay claim to as many papers as possible as falling within the field's domain. As a result, the authors classify papers that only have a tangential connection to accounting, or which do not concern ethics in the first place, as belonging to the AIS literature.

Having identified that shortcoming in the AIS-ethics literature, I propose a definition of ethical dilemmas that provide a greater degree of clarity for when ethical issues arise in a business context. That definition is intended to aid future researchers to establish AIS-ethics on a firmer footing.

The next section of the paper examines the definition of ethics in the AIS-ethics literature, especially by Dillard and Yuthas (2002) and GHNT. Section 3 undertakes a detailed analysis of what those papers puts forward as examples of AIS-ethics. That leads to my conclusion that many of these examples are less clear-cut as instances of ethics and/or of AIS. Section 4 then develops a model of when an individual feels that they face a decision with an ethical dimension to facilitate future AIS-research. Section 5 offers concluding comments.

\section{THE MEANING OF ETHICS IN THE AIS CONTEXT}

Ethics is one of the oldest disciplines of human thought. The Oxford English Dictionary provides this definition of ethics: "The branch of knowledge or study dealing with moral principles."' Similarly, Webster's Dictionary defines ethics as "an area of study that deals with ideas about what is good and bad behavior: a branch of philosophy dealing with what is morally right or wrong. "7 Webster's goes on to say that ethics can be a theory or system of moral values, the principles of conduct governing an individual or a group, a guiding philosophy or a

\footnotetext{
${ }^{6} \mathrm{http}: / /$ www.oed.com/view/Entry/64755? redirectedFrom=ethics

${ }^{7}$ http://beta.merriam-webster.com/dictionary/ethic
} 
consciousness of moral importance. The second of these is the primary focus of Business Ethics, and that is also the approach I take in this paper: in particular, emphasizing the principles of conduct of individual decision makers in AIS.

The study of ethics goes back millennia, with it being the subject of treatises by the great Greek philosophers Plato, Socrates and Aristotle. ${ }^{8}$ As the modern definitions indicate, the study of ethics is closely related to that of morality, and of philosophy in general, and is vast in range, with entire university courses and textbooks devoted to the subject (Thiroux \& Krasemann, 2015). The emerging literature on ethics in AIS, while building on this rich heritage of thought in ethics, is based on the much more modern subset of ethics research that focuses on ethical issues in business. That is a topic that has surged to prominence over the last few decades in the wake of such scandals as Ford (with its flammable Pinto vehicle), Enron, and WorldCom, the 2008 financial crash and, more recently, VW. For instance, the way MBA students are taught (and not-taught ethics) has been blamed for the way in which banks behaved prior to the collapse of the mortgage sector that resulted in the Great Recession (Di Meglio, 2009).

Given the enormity of the topic, how do AIS researchers approach ethics? Dillard and Yuthas (2002) adopt the dictionary meaning of the term when they write: "Ethics is the label given to the philosophical study of morality and considers the principle questions of 1) what ends ought a fully rational human being choose to pursue; and 2) what principles should govern the choices." What they do not do is to define what the key phrases "morality", "ends" and "principles" mean to them in the AIS context. In practice, however, their interpretation of ethics is based on the long studied relationship between ethics and politics. Thus, their paper is aimed at making the point that (emphasis added): "there is a need to acknowledge the political nature of AIS activities and choices. This is especially critical in AIS ethics research. Failure to acknowledge the political nature of one's actions and/or to adopt alternative perspectives in ethics research results in the misrepresentation or ignorance of organization influences, unquestioned maintenance of the status quo, a reinforcing of dominant regimes, the perpetuation of power asymmetries, and centralization of control. In conducting AIS ethics research, it must be kept in mind that frameworks and paradigms both

\footnotetext{
${ }^{8}$ https://en.wikipedia.org/wiki/Aristotelian_ethics
} 
enable and constrain the resolution of problems of social integration. In order for the context and consequences of AIS ethics research to be understood, there must be a recognition that historical and social conditions play a role in the dominance of specific frameworks over time. If accounting as a discipline and profession is to survive, it must move beyond the narrow functionalist, utilitarian based ethics of neoclassical economics. It must broaden its perspective beyond the privileged status of stockholders and accept a broader view of the public interest as its primary responsibility."

This political approach to ethics can be traced back at least to the seminal paper by Markus (1983) that has 3142 citations on Google Scholar'. Williams (2005) summarizes the message of Markus (1983): “The distribution of power is an ethical issue... In a classic article on "Power, Politics, and an MIS Implementation," Lynne Markus describes how a centralized accounting system elicited enormous user resistance precisely because of its impact on the power structures of a firm. By centralizing the accounting system, management hoped to create new efficiencies, reduce labor costs, and create a common financial picture throughout the firm. End users, however, read between the lines of this justification and believed that the centralized system was in fact an attempt by management to consolidate more power at headquarters. Notice that the technology itself - a combination of hardware and software for monitoring financial information-may arguably have been value-neutral. However, its application was not viewed as value-neutral by end users because it seemed to take power from them while increasing the power of centralized management. These examples demonstrate the heart of this issue: In practice, information systems are inherently laden with values and thus are ethically charged. That does not mean they are "bad" or "evil" or "unjust." It does, however, necessitate reflection before implementing such systems."

Williams' (2005) use of the word "inherently" with respect to information system echoes the arguments of the AIS researchers that ethics is prevalent in that area too. Given that, it is interesting to note that neither GHNT nor Dillard and Yuthas (2002) cite Markus (1983) in their surveys of AIS ethics. This, despite the fact that Markus (1983) actually examines in her paper the implementation of an AIS

\footnotetext{
${ }^{9}$ As of 12/17/2019 11:03:37 AM.
} 
system! In that light, it is doubly ironic that nowhere in her own article does Markus (1983) mention the word ethics. Instead, she is concerned with the topic of resistance to change, and her introduction of the political aspects of that did not imply a value judgment as to whether the change was inherently good or bad-in other words, whether there was an ethical issue involved. The title of Markus's paper, "Power, Politics and MIS Implementation", is also instructive in that it explicitly mentions management information systems. In other words, in her own work and in the subsequent research that it generated, Markus (1983) demonstrates the flexibility of what is considered to be the domain of ethics, as well as the fact that it is a subject that has a long track record in fields that are broader than AIS itself.

Apart from raising the fundamental question of whether AIS ethics research is opening up new ground or going over already plowed land, the way in which Markus (1983) has been utilized by subsequent authors shows the need to be very careful in defining what an ethical question is in the first place. What endures in the literature that has grown from Markus (1983) is the notion that, as Williams (2005) says, "the distribution of power is an ethical issue", while downplaying the actual topic of that paper, which was the resistance to change by workers to a specific technology implementation. The real lesson is the need to be mindful of exactly when technology leads to ethical problems and when it does not.

In contrast to the Markus (1983)/Williams (2005)/Dillard and Yuthas (2002) conception of ethics as power based, GHNT define ethics in terms of human rights: "We define ethics using a universal approach. Unethical actions are those judgments and behaviors enacted by humans (individuals or groups) that “...inherently deny another person or creature some inalienable right." (Paul \& Elder 2013, 14). Human rights include life, freedom, and security (among others), to all, without distinction of any kinds (e.g., race, color, sex, religion, status, etc.) (United Nations, 1948)." The reference to the UN is to the Universal Declaration of Human Rights, which begins with the preamble, "Whereas recognition of the inherent dignity and of the equal and inalienable rights of all members of the human family is the foundation of freedom, justice and peace in the world". ${ }^{10}$

\footnotetext{
${ }^{10} \mathrm{http}: / /$ www.un.org/en/universal-declaration-human-rights/
} 
As to Paul and Elder (2013), they summarize their thinking about ethics when they write: "The ultimate basis for ethics is clear: Human behavior has consequences for the welfare of others. We are capable of acting toward others in such a way as to increase or decrease the quality of their lives. We are capable of helping or harming. What is more, we are theoretically capable of understanding when we are doing the one and when the other. This is so because we have the capacity to put ourselves imaginatively in the place of others and recognize how we would be affected if someone were to act toward us as we are acting toward others." Though Paul and Elder (2013) are careful to draw a distinction between ethics and any particular religion, their definition is clearly a variant of the "Golden Rule": "do unto others as you would have them do unto you". ${ }^{11}$

When attempting to create a new field of AIS-ethics it is problematic that its proponents cannot agree on what the appropriate definition of ethics is in that field to begin with. Another problem with the definitions of both GHNT and Dillard and Yuthas (2002) is that they are too abstract to provide much practical guidance. Thus, GHNT provide no examples of ethical problems, either in AIS or outside it, in which an accountant would have to turn to the UN Declaration for Human Rights for direction on how to proceed-however commendable the sentiments expressed in that document might be. Similarly, it is hard to imagine that many accountants know what neoclassical economics is, let alone wish to "move beyond it" as Dillard and Yuthas (2002) urge them to do. ${ }^{12}$

This is a more general problem with the business ethics literature as noted by Smith and Hasnas (1999) who write: "the problem with attempting to apply these Igeneral ethical] theories directly to ethical issues in business is that they are expressed in language not easily accessible to non-philosophers. As has been observed: "People who have been trained in engineering, computer science, and management information systems, frequently have little training in ethics, philosophy, and moral reasoning. Without a vocabulary with which to think and talk about what constitutes an ethical computing issue, it is difficult to have the necessary discussions to develop social norms" (Conger \& Loch 1995, p, 36). Unfortunately, the doctrines of philosophical ethics are highly abstract and are

\footnotetext{
${ }^{11}$ Luke 6:31. King James Bible. All major religions have their own version of the Golden Rule.

12 GHNT and Dillard and Yuthas (2002) are only two of many possible formulations of ethics in accounting. Satava, Caldwell and Richards (2006) apply no less than ten ethical perspectives to accounting and auditing.
} 
essentially meaningless to one with little or no philosophical training." Similarly, Bull (2009) cites Smith and Hasnas (1999), writing: "Ethical theories are perceived to be 'too abstract', not easily accessible to people from a business, engineering, computer science or IS background... [Smith \& Hasnas (1999)] remedy this problem by diverting away from philosophical ethics for a more 'accessible' form of ethics e.g. theories of business ethics; stockholder, stakeholder and social contract theory. Although it also acknowledged that such theories are barely used in IS, despite their more accessible/practitioner nature."

The "more accessible form of ethics" that Bull (2009) alludes to, with the avoiding of overall theories of ethics in favor of context specific guidance is important because that is precisely the approach adopted by the AICPA and the Institute of Management Accountants (IMA). AICPA (2014) addresses ethics through the Code of Professional Conduct. ${ }^{13}$ The Code specifies that "In carrying out their responsibilities as professionals, members should exercise sensitive professional and moral judgments in all their activities" without specifying exactly what these "moral judgments" involves. Indeed, that is the first and last mention of morality in the entire 186-page document. Instead, the AICPA provides a comprehensive set of guidance for what happens in particular situations that CPAs might find themselves in that poses ethical problems, such as receiving gifts from suppliers, pressure to manipulate earnings and so forth.

In contrast to the lengthy rule-based AICPA guidance, the IMA favors principles, issuing a far shorter, two page, Statement of Ethical Professional Practice, which states: "IMA's overarching ethical principles include: Honesty, Fairness, Objectivity, and Responsibility. Members shall act in accordance with these principles and shall encourage others within their organizations to adhere to them." I4 Interestingly, the word "morality" never appears in the IMA code at all. Both professional bodies treat ethics very differently than do AIS ethics researchers, providing practical guidance rather than overarching definitions. ${ }^{15}$

\footnotetext{
$13 \mathrm{http} / /$ www.aicpa.org/Research/Standards/CodeofConduct/Pages/default.aspx

14 http://www.imanet.org/docs/default-source/generalpdfs/statement-of-ethics_web.pdf?sfvrsn=2

15 For alternative analyses of the AICPA Code of Professional Conduct, see Gaumnitz and Lere (2002), Lere and Gaumnitz (2003), Satava Caldwell and Richards. (2006) and Spalding and Oddo (2011). Brown, Stocks and Wilder (2007) dismiss the code as an example of "impression management".
} 
To put this discussion of the definitions of ethics into context, I now examine the type of ethical problems examined in the AIS-ethics literature.

\section{EXAMPLES OF ETHICAL PROBLEMS EXAMINED IN THE AIS- ETHICS LITERATURE}

When one considers an undisputed subset of ethics, Bioethics, it is evident that its role is to provide guidance on how to deal with ethical problems that specifically arise from advances in medical technology, such as gene editing, stem cells and human cloning. Similarly, Insurance Ethics addresses such specific problems as the ethical implications of Directors' \& Officers' insurance (Baker \& Griffiths, 2007) or third-party life insurance settlements (Nurnberg \& Lackey, 2010). The same level of specificity can be found in other subset of Business Ethics, such as Marketing Ethics. In this section, I examine GHNT, and Dillard and Yuthas (2002), to see if they have identified comparable AIS-specific ethical issues, which, in my opinion, is a prerequisite for AIS-ethics to establish itself as a distinct subset of Business Ethics.

As mentioned in the introduction, though, the main survey papers in AIS ethics provide very few examples of ethical quandaries relating to AIS in particular, with many of those listed relating to wider issues of technology and business. For instance, both GHNT and Dillard and Yuthas (2002) have extensive discussions of data privacy, which is undoubtedly a critical concern in the digital age, but hardly specific to AIS. Indeed, the privacy example in GHNT concerns credit cards, while many of the papers Dillard and Yuthas (2002) cite on privacy are from marketing.

Both surveys also discuss deskilling in the face of the development of expert systems or artificial intelligence software (AI), and there certainly already exists a large literature on deskilling written by AIS researchers (for example, Sutton \& Byington, 1993; Sutton, Arnold \& Arnold, 1995, Dillard \& Yuthas, 1997). Deskilling, though, is a concern that many professionals face today, be it doctors working in teams (Zafar \& Sadiq, 2007) or airline pilots who lack skills to deal with emergencies since so much flying on modern aircraft today is actually done by the autopilot. ${ }^{16}$ Boddy and Buchanan (1986), for example, discussed computers and deskilling more than three decades ago.

\footnotetext{
${ }^{16} \mathrm{http} / /$ www.faa.gov/aircraft/air_cert/design_approvals/human_factors/media/oufpms_report.pdf.
} 
Why does this matter? Because if the ethical issues that arise with the deskilling of accountants are the same that arise with the deskilling of supermarket cashiers, then there is little to be gained from AIS researchers writing about the former when there is already a large literature in business ethics on deskilling in general. To be clear, I am not saying that deskilling is not an important issue, or that it does not raise major ethical concerns. Only that AIS researchers cannot claim to be uniquely qualified to address the issues that it raises unless they can make the case that there is something distinctive about deskilling in the accounting profession, as opposed to deskilling in any other line of work.

I now turn to the first specific example of an ethical issue in GHNT: on page 2 they write: "The more technology evolves, the farther the actor is removed "from the consequences of organizationally sanctioned" actions (Dillard 2003, 13), reducing personal responsibility and enabling neutralizations. In other words, systems legitimize individual wrongdoing by allowing people to focus on their duties within the system, without consideration of the moral impact of their actions (Adams \& Balfour, 1998). A striking example of this occurred when a German subsidiary of IBM helped Hitler's Third Reich carry out the Holocaust by providing technology that allowed the Germans to catalog Jewish and other citizens through people counting and registration technologies (Black \& Wallace, 2001; Dillard, 2003). By treating people as inventory, the Third Reich dehumanized them, allowing Nazis to distance themselves from their actions of mass extermination."

Several important issues arise when considering this example. First, what is the ethical issue here, and in particular, what role does technology play in that ethical problem? Second, what lessons are meant to be drawn from including this example as the opening vignette in a survey of AIS ethics?

The culpability of those supplying technology for the pursuit of the Holocaust was firmly established in the post-war trials of war criminals, for example, by the execution of Bruno Tesch, the inventor of the notorious poison gas Zyklon B, and the trials of executives of IG Farben that manufactured the chemical. ${ }^{17}$ On the other hand, no manufacturer of barbed wire was tried despite the fact that it was the "technology" that literally imprisoned those held in concentration camps.

${ }^{17}$ http://www.wollheim-memorial.de/en/prozesse_wegen_der_lieferung_von_zyklon_b_an_die_ss_19461955 
The accusations against IBM, which began with Black (2001) and was subsequently picked up by Dillard (2003) and reiterated by GHNT, is that they sold a precursor of a data management system using punch cards (the "Hollerith system") to the Third Reich to undertake the 1933 census that facilitated the eventual registration of Jews and other "undesirables" marked for extermination. However, the question is whether the reason that IBM's actions are considered unethical was due to the nature of the technology itself, or the fact that the firm was conducting business with the Nazi regime in the first place. Would, for instance, IBM's critics really be less incensed if the Hollerith technology had been used to process payroll for the Wehrmacht instead of census records for the Holocaust? ${ }^{18}$ As Black (2001) admits, IBM was only one of many American companies that "refused to walk away from the extraordinary profits obtainable from trading with a pariah state such as Nazi Germany."

Indeed, in a review of Black (2001) published in the New York Times, Bernstein (2001) wrote: "The problem of moral calibration combines here with the problem of historical context. Certainly, it was clear almost as soon as the Nazis took formal power in 1933 that they were bad: they were rearming, engulfing neighboring territories, building concentration camps and savagely mistreating the Jews. Still, it was not clear until at least 1942, even to many Jews, that genocide was not only the Nazis' goal but also a goal they were determined to achieve."

This is not the time or place to debate the culpability of IBM and other American firms that did business with the Third Reich, but the point I am making is that it is too facile to use this case as a clear-cut example of an ethical issue with technology, let alone AIS technology.

Moreover, the desire to force-fit an ethical dimension to the use of technology can lead to unfortunately wrongheaded (to say the least) statements such as: "By treating people as inventory, the Third Reich dehumanized them, allowing Nazis to distance themselves from their actions of mass extermination." The Third Reich was no doubt happy to make use of technology to facilitate the killing they had planned to undertake, but the Einsatzgruppen death squads of the SS managed to slaughter two million people in the Baltic States and the USSR by shooting

\footnotetext{
${ }^{18}$ Consider the criticism by Mayer (2016) of sales by businessman Fred Koch to the Nazi regime of oil refining equipment.
} 
them in the head, up close and personal, despite the absence of the IBM technology. ${ }^{19}$ As Stargardt (2015) makes clear, Germans from all walks of life were able to accommodate themselves to the killing of non-combatants thanks to their own inherent anti-Semitism, the brutalization brought about by total war against the USSR and the internalization of Nazi propaganda. Bernstein (2001) makes the same point with great eloquence: "But such vaunted language - cards, lives and dollars fatally intersecting - threatens to obliterate the moral distinction between the sellers of rope and those who use rope to hang people." Stating that technology dehumanized Jews in Nazi Germany is to confuse means with ends and is an example of assigning ethical concerns to a technology when the context in which that technology was utilized should be the real focus of attention.

A similar lesson arises from what GHNT discusses as an example of an AISethics paper. Reviewing Tuttle et al. (1997), GHNT state: "This study examines the effects of incentives and system design on system implementation. System design is a technological factor. Company-provided extrinsic incentives (in this study, bonuses for on time and within budget delivery) are an organizational factor, which create a moral hazard for the decision-maker. Judgment surrounding the implementation of a new system is affected, resulting in an ethical dilemma: implementation of a sub-optimal system. This study does not examine environmental and human factors that may mitigate the effect of incentives on system implementation decisions. Therefore, professional standards, experience, and level in the organization are among a number of factors that might be included in future research."

The highlighted words refer to the ETHOs model of GHNT, which I will examine later in this paper. The focus here is on the interpretation of Tuttle et al. (1997) as an example of AIS-ethics research. In that regard, it is worth nothing that this paper was published in an information systems journal, never mentions the term AIS and the word accounting itself appears mainly in describing the affiliations of the authors. ${ }^{20}$ Tuttle et al. (1997) is a survey-based experimental paper in which

\footnotetext{
${ }^{19}$ https://en.wikipedia.org/wiki/Einsatzgruppen

20 As mentioned before, the appropriation of papers published in other streams of literature into the AIS ethics field is prevalent in the survey papers, but never openly acknowledged as one might imagine good ethics would require. Would the original authors agree with this ex-post reclassification of their paper?
} 
the respondents were chosen on the basis that they were "information system professionals" with particular responsibility for systems development (86 of the 146 respondents did list "Accounting or business information systems" as their education area).

However, whether or not this is counted as an AIS ethics paper is secondary to concerns raised by the task that the respondents were asked to imagine that they were carrying out. Understanding that is very insightful for developing a map of when ethical issues arise, regardless of whether that is in the AIS domain, or more generally. That requires undertaking a detailed examination of Tuttle et al. (1997) in a way that GHNT fail to do. As the title of their paper, "Moral Hazard, Ethical Considerations, and the Decision to Implement an Information System" suggests, Tuttle et al. (1997) is interested in the extent to which behavior in the implementation of an information system is affected by hidden action, the presence of incentives and the inherent degree of ethics of the participants (the last point makes GHNT's declaration that the paper does not have a human factor surprising).

In the survey, the respondents were instructed to act as "a systems development project manager in a large consulting company", with no obvious references to AIS. Tuttle et al.'s (1997) survey instrument operationalizes these factors by presenting participants with a scenario in which they have to decide whether to go ahead or delay the implementation of an information system (labeled "Project Y") which is experiencing some difficulties: "You manage Project $Y$, the total reengineering of the inventory order system for an important client. The client is pressing you to implement the system now, as scheduled, so that it will be operational prior to the peak order season six months from now. You are concerned that the order system may not be ready to implement and expect to have some quality problems if Project $Y$ is implemented now as scheduled. If you implement now, as scheduled, these quality problems are likely to result in lower user satisfaction after the project is complete. A delay, however, requires you to postpone implementation for at least nine months until after the client's peak order season. This means Project $Y$ will fall substantially behind schedule and will be seriously over budget due to considerable extra expenses associated with the delay. Thus, the only way to stay within budget and on schedule is by implementing Project Y now and working through the quality problems later." 
The authors turn two dials at once by having hidden action and pay-forperformance in the "Yes-Moral-Hazard Condition" and full transparency and quality-based compensation in the "No-Moral-Hazard Condition". Respectively:

- $\quad$ "You will lose a substantial portion of your usual compensation unless you implement Project $Y$ now, as scheduled... if you implement the system now, as scheduled, your superiors will never know that Project Y had unresolved quality problems."

Versus,

- $\quad$ "You will lose a substantial portion of your usual compensation unless you delay implementation of Project $Y$ until the quality problems are worked out... unless you delay implementation, your superiors will immediately know that you implemented a project with unresolved quality problems that will result in lower user satisfaction after the project is complete."

What is noteworthy is that it is only in the first condition that there is a substantive decision to be made. In the No-Moral-Hazard Condition, it is obvious that the project should be delayed until the problems with it are resolved-which makes it inexplicable that some one third of respondents decided to implement the project even in this case when the firm makes its preferences for quality over speed of implementation quite explicit. The authors do not comment on this result, though, since their focus is on the Yes-Moral-Hazard Condition where they state: "implementing the system now despite its quality problems favors the manager's self-interest and is contrary to the stated objective of their firm."

However, is that accurate? Unlike in the No-Moral-Hazard Condition it is actually not clear what the firm would want the manager to do in this case. It is true that at present Project $Y$ has difficulties, but the survey instrument indicates that this has to do with its ease of use and not necessarily with it being able to function as designed in dealing with inventory orders (recall the statement above that "If you implement now, as scheduled, these quality problems are likely to result in lower user satisfaction after the project is complete.") That outcome on internal dissatisfaction with the system has to be traded off against the "considerable extra expenses" from delaying the project. It is not made clear whether these extra expenses encompass only the additional cost of a delayed project or also include 
the opportunity cost of lost sales and profits due to inefficient handling of inventory orders during the firm's peak order season.

In either case, but especially in the second, there is no guidance given to the manager about how he or she is to balance the costs of delay versus the costs of implementing immediately. In other words, and contrary to what the authors claim, there is not necessarily a clear cut situation here of moral hazard, in which the only argument for implementing the system immediately is the personal benefit from the pay-for-performance scheme, and with the firm always worse off as a result. Even if that ends up being the case, the managers can argue that their decision was not contrary to the instructions and incentives that they were given by their superiors and, hence, that they are not acting unethically as Tuttle et al. (1997) argue that they are doing.

It is important to understand that my point with this analysis is not to criticize Tuttle et al. (1997). I have focused on their paper only because GHNT did so, and their scenario is actually extremely helpful in identifying when ethical issues are likely to arise: when there is a lack of explicit guidance by the firm to the employee about how they are to make a decision in a specific context. In the NoMoral-Hazard Condition the firm's intentions are aligned with the controls under which the participant operates, but in the Yes-Moral-Hazard Condition managers are left to their own devices to determine which cost is higher, that of delay or that of a flawed implementation. That is an important lesson from this example that I will develop later into a model of ethics.

As mentioned before, the main purpose of both GHNT and Dillard and Yuthas (2002) seems to be to claim as many papers as possible as falling in the domain of AIS-ethics - even when those papers are from outside accounting — on the basis that they share a common activity with AIS (such as data management or privacy). But the end result is a set of papers whose relation to AIS specifically is low, with papers falling into such generic categories as "privacy", "accuracy", "property" and "workplace issues" in the case of Dillard and Yuthas (2002). What is needed is a way of identifying AIS-specific ethical dilemmas by beginning with the ethical issue involved rather than with a generic activity.

To facilitate that process, I conclude this section by providing an example of my own of an ethical dilemma arising from the interaction between new technology and established work practices. As with the two examined above by GHNT and 
Dillard and Yuthas (2002), it is not drawn from AIS, but it does involve the interaction between technology, behavior and control systems - and does so in a context which AIS ethics researchers can easily identify with: the process at the end-of-semester in which students are surveyed in order to evaluate their instructor. For many years, this survey was paper based, but now it is administered online in most institutions and it is the ethical issues that arise because of that shift to web based reporting that I wish to examine.

Probably since its inception there has been complaints that the student survey does not measure the quality of instruction, especially not the single question that chair's and dean's tend to focus on, which evaluates the "effectiveness" of the instructor along the lines of: "I rate the teaching effectiveness of the instructor as:". That is not the central issue I am raising here. Rather, it concerns the reasons for shifting the administration of the forms to online. That may have partly been due to the reduction in effort that results from it being all digital but the main purpose was to prevent instructors from "gaming" the system when the survey was manually administered. Thus, in my own experience, some instructors played musical instruments, brought along cookies or pizza "to celebrate the end of the semester" gave detailed exam reviews or undertook other such student-pleasing gestures on the day that the evaluation form was handed out. ${ }^{21}$

Implementing an online survey may solve these problems to some degree, but they create a major new issue: the large reduction in response rate, especially by those students who did not feel strongly about the class and/or the instructor. Based on my own experience of listening to complaints made at faculty meetings, many instructors are concerned that the online survey results in responses mainly by students with an ax to grind, thus resulting in instructor ratings that are harsher and less representative of all students. The fact that these complaints are not entirely self-serving can be assessed from the rather extraordinary addition that was recently made to the instructions for the survey emailed to instructors at my current university: "To promote student participation, you may want to set aside some class time for students to complete the survey." Obviously, this suggestion reverses much of the benefits of the online survey as a tool to reduce gaming by

\footnotetext{
${ }^{21}$ Equally, some students vied to volunteer to collect the forms when the instructor left the room — as required - when the students filled the forms out, as a last attempt to ingratiate themselves before grading. Lest I be accused of unethical disclosure myself, I hasten to add that these anecdotes encompass multiple institutions over the years.
} 
faculty, especially as there is apparently no requirement anymore that faculty leave the room when students fill out the survey, as there used to be when it was paper based.

The underlying ethical issue in this example arise from the concerns of faculty that the student instructional survey, and especially that one question on instructor effectiveness, does not adequately measure the quality of the work that they put into the class. ${ }^{22}$ Consequently, some instructors feel that they have no choice but to take actions to boost response rates and generate higher ratings, especially when they are facing re-appointment decisions in the case of adjuncts, or tenure and promotions decisions in the case of tenure-track faculty. ${ }^{23}$ These behaviors, which may well be perceived as unethical by some, take place not just at the end of the semester, when the survey is open for student to complete, but throughout the course-for example, by making the course less rigorous, not taking attendance, excessive "hand-holding" of the students and turning a blind eye to cheating. ${ }^{24}$ The pressures on faculty to act in this way are exacerbated when administrators make changes, such as the switch to the online survey, without giving any indication that they have anticipated and made allowance in performance evaluation procedures for the negative consequences on instructors of the change.

Again, I emphasize that the intent of this example is not to complain about the student evaluation form, but to highlight the unforeseen ethical issues that arose due to changes in the technology by which it is administered. It is that aspect of the example that has implications for AIS-ethics.

In this regard, this example of the student survey dovetails with that of Tuttle et al. (1997) in that both examine behavior in the absence of clear controls that address all eventualities. Whether the consequent behavior is unethical, a rational

\footnotetext{
22 There is research on this question, much of it with mixed results as to the mean of the response, but clear as to the reduction in participation rate brought about by the shift from paper to online administration (see the references at https://www.ets.org/sir_ii/about/research/). Note that what drives the ethical issues is the perception of faculty, and whatever the research, many instructors consider the web based survey to be unfair.

${ }^{23}$ Note, too, that the summary of the survey results usually gives ratings both in absolute terms, and relative to other faculty in the department. Thus, instructors are also motivated by the need to keep pace with the tactics used by their colleagues to boost their own scores.

${ }^{24}$ All of which I have either done or seen other faculty do.
} 
response to the lack of guidance, or both is a matter of debate. What these examples indicate is that there needs to be a more rigorous way of identifying precisely when a decision maker in AIS — or any other field - faces an ethical dilemma.

\section{SYNTHESIZING A NEW DEFINITION OF ETHICS}

As the discussion in Section 2 above indicates, ethics arises at the policy, social and/or organizational level as well as that of the individual. There are also settings in which an individual genuinely feels that they are doing the right thing, while an outside observer equally sincerely considers that that those actions are unethical: that, after all, is the reason why societies have "culture wars".

Indeed, the popular discussion of ethics often consists of one party demanding that another acknowledge the [to them, self-evident] fact that the others' behavior has ethical implications: that their behavior is "wrong", not just in terms of being the incorrect solution to a problem, but also morally abhorrent. Examples abound, including corporate social responsibility, climate change, use of fossil fuels, purchase of conflict minerals or products made with child or exploited workers, trade with South Africa in the past or Israel today, actions perceived as pro and anti-gay and on and on, with any perusal of the media adding to this list. Clearly, these matters do not in fact genuinely involve ethical aspects, but that is also the problem: normatively imposing an ethical standard upon someone else's behavior is both subjective and all too easy.

It is my contention in this paper that in order to prevent the reduction of ethics to a mere debate about which person's opinion is right and whose is wrong, the focus has to return to the actual decision maker and the circumstances under which they recognize that their behavior has an ethical component to it. There is an old saying that "temptation is easier to resist than to find". In other words, in order for an individual to have to make an ethical decision they first have to find themselves in a situation in which they feel unsure about what course of action feels "right" to them.

This approach is the equivalent of beginning microeconomics with individual preferences and only then deriving supply and demand curves based on that model of consumer behavior. In the absence of a personal dimension, ethics becomes an argument between individuals rather than a dilemma for an individual. Paralleling 
the economics perspective, my approach to ethics is to go back to first principles to ask, "What does ethics mean to an individual making a decision?"

My micro approach to ethics contrasts with GHNT's macro ETHOs model (Figure 2) that they developed in order to classify the AIS ethics research literature by the Environmental, Technological, Human and Organizational factors considered in each paper. GHNT then extended their model in a more general direction when they write: "Researchers may use the ETHOs framework to both understand existing literature, and to identify, develop, and examine relevant research questions related to AIS and ethics. The ETHOs factors influence judgment, decision-making, and actions (JDMA) individuals make when carrying out the AIS functions of recordkeeping, reporting, or control."

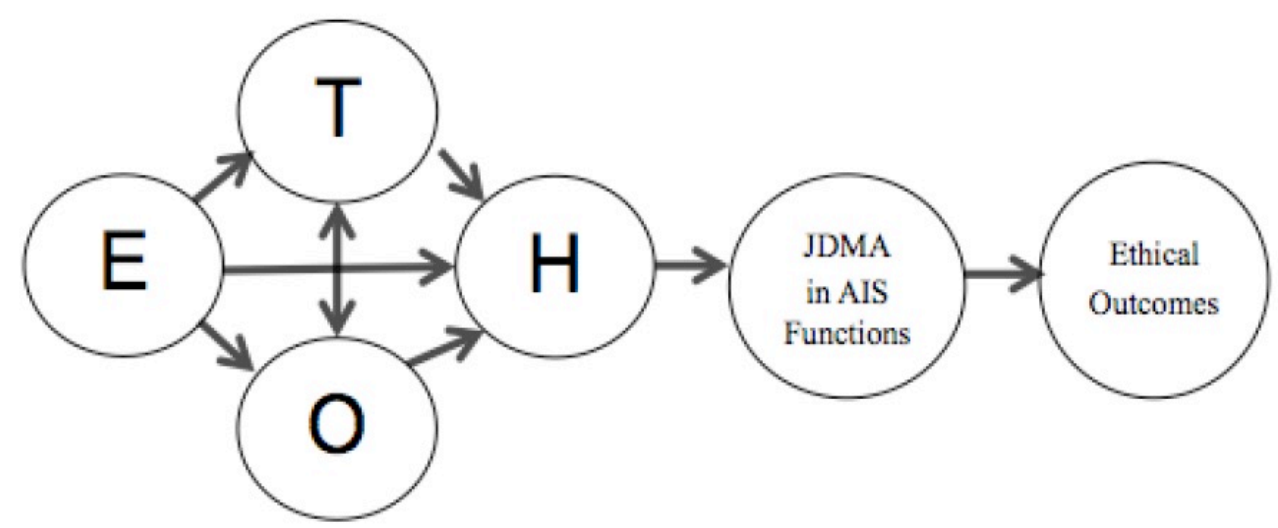

Figure 2. ETHOs model from Guragai Hunt, Neri and Taylor (2017)

While the ETHOs model identifies the factors that influence decision-making by individuals that is also its' failing: it is so generic as to be virtually a tautologyand it applies to any decision, not just one involving ethics. As such, the model cannot identify when ethical problems in particular are likely to arise. To develop a model that overcomes these shortcomings requires the adoption of a perspective that places the agency of the individual at the center and which defines what it means for that individual to face an ethical problem.

As Smith and Hasnas (1999), and Bull (2009) wrote, many characterizations of ethics are too remote or esoteric from the day-to-day concerns of practitioners in AIS or any other field to have much resonance with them. At its simplest, though, ethics "deals with ideas about what is good and bad behavior", as the Webster's 
Dictionary puts it. Since virtually all behavior may have good or bad outcomes given the context in which they take place, a more useful question is why do ethical concerns only arise with a small subset of the numerous actions individuals undertake in the course of living their personal and professional lives?

The reason, of course, is that most human behavior is mundane and nonproblematic because the individual is simply doing what tradition, accepted morality, the law, regulation or the controls imposed by the organization under which they work expect of them. In short, the decision maker does not feel that those decisions involve any ethical challenge - either because they see no ethical aspect to the decision, or if they do, it is self-evident to that individual what is the "right" thing to do. ${ }^{25}$ Indeed, not even the most ethically trained and aware person analyzes the ethical implications of each decision they make during a day, because not only is that a scenario for paralysis (or a nervous breakdown), but because it is not necessary as far as they are concerned.

As the scenario of Tuttle et al. (1997) and the example of the student instructor survey showed, where ethical problems arise is when those default sources of guidance fail to cover - at least in the perception of the individual - the decision context that they face. Thus, in the Yes-Moral-Hazard Condition of Tuttle et al. (1997) the manager is both incentivized to minimize the cost of the implementation and told to achieve high quality, but not given the criteria for trading one objective against the other when they are in conflict. In the teaching example, the instructor has a responsibility to provide high quality, rigorous education, but is evaluated using a metric that they perceive as being based more on the popularity of the teacher with the most strident students than on the pedagogical outcomes of the class as a whole. Whether that perception is objectively correct is not the issue: what matters is that instructors feel that they are placed in a situation in which they are tempted to take actions they would not otherwise do in order to retain their jobs. ${ }^{26}$

\footnotetext{
${ }^{25}$ Of course, an outside observer might disagree.

${ }^{26}$ Note that this last example can be enriched using the ETHOs framework of GHNT to provide context. I have already discussed the role of technology: whether the survey is administered on paper or online. There is also the environmental factor of whether the instructor is tenured or an associate on a short-term contract, while the organizational factor could be the use of class visits by other experienced faculty in order to supplement the student feedback with a more objective viewpoint. An important human factor is the talent of the teacher and their self-confidence that they can be both rigorous and popular. This application of the ETHOs model is most useful after the identification of the reason for why the individual found themselves having to face an ethical problem in the first place, and that is the lack of guidance about how
} 
Based on the analysis in the first part of this paper, I put forward my own supposition for when an ethical dilemma arises:

A necessary condition for individuals to consider that they face a decision with ethical consequences is that they perceive that there is a conflict between the behavior allowed under their sense of morality (meaning their "conscience", or other personal criteria for judging what is right from wrong) and the behavior required under the other sources of guidance which comprise the decision criteria that they consider to be relevant towards making that decision.

All decisions involve a choice between alternatives and possibly conflicting decision criteria, but there has to be a moral component for that decision to rise to the level of an ethical dilemma. If there is no conflict between the behavior sanctioned under morality and other sources of guidance, then there remains a decision to make, but it is one without ethical implications as far as the decision maker is concerned. If the decision alternatives are outside all established mores then the decision is clearly unethical, even illegal. The reason for stating the supposition as a necessary and not a sufficient condition is than an individual has to actively choose to acknowledge an ethical dimension to a decision problem, and history indicates that most people will most often choose the option that involves the least personal cost. In other words, they can choose to deny that their sense of right or wrong is at stake.

By defining ethics as the non-intersection between morality and other decision criteria, the supposition might seem to be as much a tautology as the ETHOs model of GHNT. This supposition, however, is particular useful for application in the business ethics area as it permits the inclusion of a role for a business's control system. The presence of a control system is one factor that distinguishes business ethics from ethics in other professional fields or from ethics as the philosophical study of human behavior in general. Moreover, the supposition facilitates the visualization of ethical problems as a way to both illustrate the underlying basis of the ethical dilemma and to teach individuals how to enhance their ethical awareness.

Synthesizing a business-oriented model of ethics is only a means towards and end, however. Further research is needed to see if it facilitates the analysis of ethical

they are supposed to act. Once that is known, the ETHOs factors become a lens to identify the specific factors that might ameliorate or exacerbate that situation rather than remaining a generic and tautological construct. 
problems unique to the AIS space, thus justifying the creation of a distinct subfield of ethics labelled AIS-ethics.

\section{CONCLUSION}

Dillard and Yuthas (2002), and Guragai Hunt, Neri and Taylor (2017) argue that ethics is present in virtually every aspect of AIS, and thus, that AIS-ethics should be considered to be a distinct a subset of ethics. AIS researchers are actually lagging in this regard, since many other professions have already successfully created field-specific spaces for ethics - and in the case of Bioethics, for instance, achieved prominent success. Indeed, Bioethics now has its own subsets, such as Pediatric Bioethics, Clinical Ethics and Neuroethics. ${ }^{27}$ As these examples show, there can be real value from marrying field-specific knowledge with broader and more generic ethical teachings.

However, such attempts can only attain success if researchers rigorously and systematically analyze when and why members of their profession encounter ethical challenges. Have AIS researchers made the case that AIS-Ethics should be recognized as a distinct subset of business ethics? I would say that the jury is still out on that question. The literature is obviously in its infancy and lacks an agreed upon definition of either ethics or of the domain of AIS. Most important of all, AIS-ethicists need to provide a means of identifying precisely when an AIS practitioner encounters an ethical dilemma.

\section{REFERENCES}

Adams, G., \& Balfour, D. (1998). Unmasking Administrative Evil. Thousand Oaks, CA. Sage Publications.

Aicpa.org. (2014). Online Code of Professional Conduct. https://pub.aicpa.org/ codeofconduct/Ethics.aspx. Accessed 5 July 2019.

Aicpa.org. (2015). Audit Analytics and Continuous Audit: Looking to the Future. Emerging Assurance Technologies Task Force. http://www.aicpa.org/Interest Areas/FRC/AssuranceAdvisoryServices/DownloadableDocuments/AuditAnalytic s_LookingTowardFuture.pdf. Accessed 5 July 2019.

Alles, M., Kogan, A., \& Vasarhelyi, M. (2008). Exploiting comparative advantage: A paradigm for value added research in accounting information

\footnotetext{
${ }^{27}$ http://www.bioethics.net/
} 
systems. International Journal of Accounting Information Systems, 9(4), 202-2. https://doi.org/10.1016/j.accinf.2008.06.001

Baker, T., \& Griffiths, S. (2007). The missing monitor in corporate governance: The directors' \& officers' liability insurer. Georgetown Law Journal, 95, 17951842.

Bampton, R., \& Cowton, C. (2013). Taking Stock of Accounting Ethics Scholarship: A Review of the Journal Literature. Journal of Business Ethics, 114(3), 549-563. www.jstor.org/stable/23433798

Bernstein, R. (2001, March 7). I.B.M. and the Holocaust: Assessing the Culpability. The New York Times.

Black, E. (2001). IBM and the Holocaust. Crown Publishers, New York.

Black, E., Wallace, B. (2001). IBM and the Holocaust: The strategic alliance between Nazi Germany and America's most powerful corporation. Crown Publishers, New York.

Boddy, D., \& Buchanan, D. (1986). Managing New Technologies. Blackwell, Oxford.

Brrown, P., Stocks, M., \& Wilder, W. (2007). Ethical Exemplification and the AICPA Code of Professional Conduct: An Empirical Investigation of Auditor and Public Perceptions. Journal of Business Ethics, 71, 39-71. https://doi.org/ 10.1007/s10551-006-9124-3

Briloff, A. (1972). Unaccountable Accounting: Games Accountants Play. Harper Collins.

Bull, C. (2009). A Review of Ethical Theory in the 'Upper Echelons' of Information Systems Research [Conference presentation]. European Conference on Information Systems (ECIS) 2009, Verona, Italy. http://aisel.aisnet.org/ cgi/viewcontent.cgi? article $=1015 \&$ context $=$ ecis 2009 .

Conger, S., \& Loch, K. (1995). Ethics and Computer Use. Communications of the $A C M, 38(12), 31-33$.

Di Meglio, F. (2009, May 20). MBAs: Public Enemy No. 1? Bloomberg Business. http://www.bloomberg.com/bw/stories/2009-05-20/mbas-public-enemy-no-dot-1businessweek-business-news-stock-market-and-financial-advice

Dillard, J. (2003). Professional Services, IBM, and the Holocaust. Journal of Information Systems, 17(2), 1-16. DOI: 10.2308/jis.2003.17.2.1

Dillard, J., \& Yuthas, K. (1997). Ethical issues in expert systems: Lessons from moral philosophy. Research on Accounting Ethics, 3, 99-117. 
Dillard, J., \& Yuthas, K. (2001). A responsibility ethic for audit systems. Journal of Business Ethics, 30(4), 337-359. https://doi.org/10.1023/A:1010720630914

Dillard, J., \& Yuthas, K. (2002). Ethics Research in AIS. In Researching Accounting as an Information Systems Discipline. Edited by Arnold, V. and S. Sutton. American Accounting Association, Sarasota FL.

Doyle, A. (2011). Introduction: Insurance and Business Ethics. Journal of Business Ethics, 103, 1-5. https://doi.org/10.1007/s10551-012-1219-4

Duska, R., Duska, B., \& Ragatz, J. (2011). Accounting Ethics. Second Edition. Wiley-Blackwell.

Eubanks, D., Brown, A., \& Ybema, S. (2012). Leadership, Identity, and Ethics. Journal of Business Ethics, 107(1), 1-3. https://doi.org/ 10.1007/s10551-0121295-5

Foot, P. (1967). The Problem of Abortion and the Doctrine of the Double Effect. Oxford Review, 5: 5-15.

Frost, N. (1992). Ethics, ethics everywhere. Current Problems in Pediatric and Adolescent Health Care, 22(10), 422-3.

Gaumnitz, B., Lere, J. (2002). Contents of Codes of Ethics of Professional Business Organizations in the United States. Journal of Business Ethics, 35: 3549. https://doi.org/10.1023/A:1012718103007

Guragai, B., Hunt, N., Neri, M., \& Taylor, E. (2017). Accounting Information Systems and Ethics Research: Review, Synthesis, and the Future. Journal of Information Systems, 31(2), 65-8. https://doi.org/10.2308/isys-51265

Javalgi, R., \& Russell, L. (2015). International Marketing Ethics: A Literature Review and Research Agenda. Journal of Business Ethics, 148(4), 703-720. DOI: 10.1007/s10551-015-2958-9.

Lere, J., Gaumnitz, B. (2003). The Impact of Codes of Ethics on Decision Making: Some Insights from Information Economics. Journal of Business Ethics, 48, 365-379. DOI: 10.1023/B:BUSI.0000005747.37500.c8.

Malik, M. (2015). Value-Enhancing Capabilities of CSR: A Brief Review of Contemporary Literature. Journal of Business Ethics, 127(2), 419-438. ttps://doi.org/10.1007/s10551-014-2051-9

Markus, M. (1983). Power, Politics and MIS Implementation. Social impacts of computing. Communications of ACM, 26(6), 443-441. https://doi.org/ $10.1145 / 358141.358148$

Mayer, J. (2016). Dark Money. Doubleday, New York. 
Nurnberg, H., \& Lackey, D. (2010). The Ethics of Life Insurance Settlements: Investing in the Lives of Unrelated Individuals. Journal of Business Ethics, 96(4), 513-534. https://doi.org/10.1007/s10551-010-0480-7

Paul, R., \& Elder, L. (2013). The Thinker's Guide to Ethical Reasoning. Foundation for Critical Thinking Press. Tomales, CA.

Satava, D., Caldwell, C., \& Richards, L. (2006). Ethics and the Auditing Culture: Rethinking the Foundation of Accounting and Auditing. Journal of Business Ethics, 64, 271-284. https://doi.org/10.1007/s10551-005-0556-y

Schlegelmilch, B., \& Öberseder, M. (2010). Half a Century of Marketing Ethics: Shifting Perspectives and Emerging Trends. Journal of Business Ethics, 93(1), 119. https://doi.org/10.1007/s10551-009-0182-1

Smith, H., \& Hasnas, J. (1999). Ethics and Information Systems: The Corporate Domain. Management Information Systems Quarterly, 23(1), 109-127.

Spalding, A., \& Oddo, A. (2011). It's Time for Principles-Based Accounting Ethics. Journal of Business Ethics, 99, 49-59. https://doi.org/10.1007/s10551-0111166-5

Stargardt, N. (2015). The German War: A Nation under Arms, 1939-1945. Basic Books. New York.

Sutton, S., Arnold, V., \& Arnold, T. (1995). Toward an understanding of the philosophical foundations for ethical development of audit expert systems, Research on Accounting Ethics, 1, 61-74.

Sutton, S., \& Byington, J. (1993). An analysis of ethical and epistemological issues in the development and implementation of audit expert systems. Advances in Public Interest Accounting, 5, 231-243.

Thiroux, J., \& Krasemann, K. (2015). Ethics: Theory and Practice (Updated Edition). $11^{\text {th }}$ Edition. Pearson, Boston.

Tuttle, B., Harrell, A. \& Harrison, P. (1997). Moral Hazard, Ethical Considerations, and the Decision to Implement an Information System. Journal of Management Information Systems, 13(4), 7-27. https://doi.org/ 10.1080/07421222.1997.11518140.

Un.org. United Nations. (1948). Universal Declaration of Human Rights. https://www.un.org/en/universal-declaration-human-rights/. Accessed 7 July 2019.

Uysal, O. (2009). Business Ethics Research with an Accounting Focus: A Bibliometric Analysis from 1988 to 2007. Journal of Business Ethics, 93, 137160. https://doi.org/10.1007/s10551-009-0187-9 
Vasarhelyi, M., Alles, M., \& Williams, K. (2010). Continuous Assurance for the Now Economy. Institute of Chartered Accountants in Australia. Melbourne.

Williams, W. (2005). IT Matters: "Ethics, Information Systems, and a Steel Ax", Graziadio Business Review, 8(2) https://gbr.pepperdine.edu/ 2010/08/ethicsinformation-systems-and-a-steel-ax/.

Zafar, R., \& Sadiq, K. (2007). Deskilling of Junior Doctors. Psychiatric Bulletin, 31(12), 467. https://doi.org/10.1192/pb.31.12.467. 